\title{
The Role of Contralesional Dorsal Premotor Cortex after Stroke as Studied with Concurrent TMS-fMRI
}

\author{
Sven Bestmann, ${ }^{1 \star}$ Orlando Swayne, ${ }^{1 \star}$ Felix Blankenburg, ${ }^{2,3}$ Christian C. Ruff, ${ }^{2,3,4}$ James Teo, ${ }^{1}$ Nikolaus Weiskopf, ${ }^{3}$ \\ Jon Driver, ${ }^{2,3}$ John C. Rothwell, ${ }^{1}$ and Nick S. Ward ${ }^{1}$ \\ ${ }^{1}$ Sobell Department of Motor Neuroscience and Movement Disorders, UCL Institute of Neurology, ${ }^{2}$ UCL Institute of Cognitive Neuroscience, and \\ ${ }^{3}$ Wellcome Trust Centre for Neuroimaging at UCL, UCL Institute of Neurology, University College London, WC1N 3BG London, United Kingdom, and \\ ${ }^{4}$ Laboratory for Social and Neural Systems Research, University of Zurich, 8006 Zurich, Switzerland
}

Contralesional dorsal premotor cortex (cPMd) may support residual motor function following stroke. We performed two complementary experiments to explore how cPMd might perform this role in a group of chronic human stroke patients. First, we used paired-coil transcranial magnetic stimulation (TMS) to establish the physiological influence of cPMd on ipsilesional primary motor cortex (iM1) at rest. We found that this influence became less inhibitory/more facilitatory in patients with greater clinical impairment. Second, we applied TMS over cPMd during functional magnetic resonance imaging (fMRI) in these patients to examine the causal influence of cPMd TMS on the whole network of surviving cortical motor areas in either hemisphere and whether these influences changed during affected hand movement. We confirmed that hand grip-related activation in cPMd was greater in more impaired patients. Furthermore, the peak ipsilesional sensorimotor cortex activity shifted posteriorly in more impaired patients. Critical new findings were that concurrent TMS-fMRI results correlated with the level of both clinical impairment and neurophysiological impairment (i.e., less inhibitory/more facilitatory cPMd-iM1 measure at rest as assessed with paired-coil TMS). Specifically, greater clinical and neurophysiological impairment was associated with a stronger facilitatory influence of cPMd TMS on blood oxygenation level-dependent signal in posterior parts of ipsilesional sensorimotor cortex during hand grip, corresponding to the posteriorly shifted sensorimotor activity seen in more impaired patients. cPMd TMS was not found to influence activity in other brain regions in either hemisphere. This state-dependent influence on ipsilesional sensorimotor regions may provide a mechanism by which cPMd supports recovered function after stroke.

\section{Introduction}

Cortical regions in the intact hemisphere are thought to be important in supporting motor function of the paretic hand after stroke (Seitz et al., 1998; Ward, 2004; Gerloff et al., 2006; Lotze et al., 2006; Cramer, 2008; Schaechter and Perdue, 2008; Schaechter et al., 2008). Contralesional dorsal premotor cortex (cPMd) is more active during movement of the affected hand after stroke compared with in healthy controls (Chollet et al., 1991; Weiller et al., 1992), particularly for more impaired patients (Ward et al., 2003b) with greater corticospinal tract disruption (Ward et al., 2006). Two further lines of evidence suggest that cPMd supports recovered motor function in these patients. First, using transcranial

\footnotetext{
Received Aug. 24, 2009; revised July 8, 2010; accepted July 14, 2010.

This work was supported by the Wellcome Trust, the Medical Research Council, the Patrick Berthoud Charitable Trust, the Biotechnology and Biological Sciences Research Council, and the European Commission under the 7th Framework Programme - HEALTH - Collaborative Project Plasticise (Contract no. 223524); www.plasticise.eu. We thank Victor Baller for construction of the MR-compatible TMS coil holder and Peter Aston, Eric Featherstone, Oliver Josephs, and Anthony Thomas for technical support. We also thank the staff of the Acute Brain Injury Unit and Neurohabilitation Unit at the National Hospital for Neurology and Neurosurgery, Queen Square, London, for their assistance.

*S.B. and O.S. contributed equally to this work.

Correspondence should be addressed to Sven Bestmann, Sobell Department of Motor Neuroscience and Movement Disorders, UCL Institute of Neurology, 33 Queen Square, WC1N 3BG, London, UK. E-mail: s.bestmann@ ion.ucl.ac.uk.

D01:10.1523/JNEUROSCI.5642-09.2010

Copyright $\odot 2010$ the authors $\quad 0270-6474 / 10 / 3011926-12 \$ 15.00 / 0$
}

magnetic stimulation (TMS) to disrupt cPMd activity during recovered hand movement can worsen performance in a way not seen in healthy controls (Lotze et al., 2006), particularly in patients with greater impairment (Johansen-Berg et al., 2002). Second, activity in cPMd when controlling force production with the affected hand is greater in the presence of more extensive corticospinal tract disruption (Ward et al., 2007).

However, the mechanisms by which cPMd can exert a functionally relevant causal influence on motor output following stroke remain unresolved. It seems unlikely that cPMd can support hand function via direct projections to spinal cord motoneurons (Boudrias et al., 2010). An alternative hypothesis is that cPMd might influence other cortical areas in the surviving motor network to support residual motor output (Cramer, 2008) and higher-order processes required for motor function (Gerloff et al., 2006). Paired-coil TMS studies have demonstrated a direct inhibitory interhemispheric influence of PMd on the output of primary motor cortex (M1) in the opposite hemisphere for healthy humans at rest (Mochizuki et al., 2004; Bäumer et al., 2006; Koch et al., 2006; O’Shea et al., 2007b). During an active motor task, this inhibitory influence can change (Koch et al., 2006; O'Shea et al., 2007a; Bestmann et al., $2008 \mathrm{~b}$ ). We assessed the influence of cPMd on surviving cortical motor regions in stroke patients with different levels of impairment to test how cPMd might support motor function in the face of partial corticospinal tract disruption via an influence on other brain areas. Furthermore, we asked whether such influences are 
Table 1. Patient details and clinical scores

\begin{tabular}{|c|c|c|c|c|c|c|}
\hline Patient & Sex & $\begin{array}{l}\text { Age } \\
\text { (years) }\end{array}$ & Site of lesion & $\begin{array}{l}\text { Time since } \\
\text { stroke (months) }\end{array}$ & Past medical history & Medication \\
\hline 1 & M & 52 & L stratiocapsular & 22 & Hypertension, AF, DM & Warfarin, insulin, ramipril, bendrofluazide \\
\hline 2 & M & 52 & R stratiocapsular & 104 & Hypothyroidism & Aspirin, pravastatin, thyroxine \\
\hline 3 & $\mathrm{~F}$ & 55 & R stratiocapsular & 6 & Hypertension, COPD, mild depression & Aspirin, ezetimide, omeprazole, salbutamol \\
\hline 4 & M & 46 & R stratiocapsular & 31 & Nil & Aspirin \\
\hline 5 & M & 59 & L pons & 13 & Hypertension, DM, gout & Aspirin, diltiazem, gliclazide, metformin, simvastatin, omeprazole \\
\hline 6 & $\mathrm{~F}$ & 84 & R stratiocapsular & 26 & IHD, hyperthyroid, AF & Aspirin, digoxin, atenolol, thyroxine, ramipril \\
\hline 7 & M & 55 & R internal capsule & 17 & Hypertension, DM, renal impairment & Aspirin, dipyridamole, insulin, frusemide, diltiazem, ramipril, atorvastatin \\
\hline 8 & M & 75 & R internal capsule & 13 & Hypertension & Aspirin, simvastatin \\
\hline 9 & M & 51 & $\mathrm{R}$ corona radiata & 4 & Diabetes & Warfarin, gliclazide, simvastatin \\
\hline 10 & M & 58 & R stratiocapsular & 9 & $\mathrm{AF}$ & Warfarin, flecainide, bisoprolol, atorvastatin \\
\hline 11 & M & 43 & R thalamocapsular & 11 & Hypertension & Bisoprolol, lisinopril, amlodipine, bendrofluazide \\
\hline 12 & M & 59 & R thalamus/insula & 84 & Hypertension, AF & Warfarin, simvastatin, propranolol, flecainamide, perindopril, amlodopine \\
\hline
\end{tabular}

M, Male; F, female; L, left; R, right; AF, atrial fibrillation; COPD, chronic obstructive pulmonary disease; DM, diabetes; IHD, ischaemic heart disease.

state dependent, i.e., change from rest to active movement of the paretic hand.

First, we tested the direct interhemispheric influence of cPMd on ipsilesional M1 in subcortical stroke patients at rest using paired-coil, paired-pulse TMS (Mochizuki et al., 2004; Bäumer et al., 2006; Koch et al., 2006). In a separate experiment with the same patients, we used concurrent TMS-fMRI to deliver TMS pulses over cPMd while measuring its causal influence on brain activity during hand grip or rest in other potentially interconnected brain areas. We sought to explain variability in the statedependent (i.e., hand grip or rest) influence of cPMd as a function of clinical and neurophysiological impairment. We thus tested which parts of the surviving motor network were causally influenced by cPMd during affected hand grip, and how this influence might vary with the level of residual motor function or in relation to the separately assessed paired-coil neurophysiological measure.

\section{Materials and Methods}

\section{Participants}

Patients were recruited from the National Hospital for Neurology and Neurosurgery, Queen Square, London. All were premorbidly right handed and had experienced a first-time ischemic stroke resulting in weakness of (at least) wrist and finger extensors and hand interossei (to $\leq 4+$ on the Medical Research Council scale), lasting a minimum of $48 \mathrm{~h}$ after the onset of symptoms. Exclusion criteria were as follows: (1) extension of the lesion into cortical motor regions; (2) carotid artery stenosis $\geq 70 \%$ as assessed by carotid Doppler studies and/or magnetic resonance angiography; (3) previous seizures or other neurological or psychiatric diseases; (4) inability to perform the grip task used during the fMRI part of our study (see below); (5) deficits of language comprehension; and (6) time after lesion $<4$ months.

Patients were not receiving active physical therapy, but had received poststroke therapy appropriate to their individual clinical needs. All patients (age, $57.4 \pm 11.6$ years) had normal or corrected-to-normal vision. Patients were naive to the purpose of the experiment. Full written consent was obtained from all participants, in accord with approval by the Joint Ethics Committee of the UCL Institute of Neurology and the National Hospital for Neurology and Neurosurgery, UCL Hospitals NHS Foundation Trust, London. Twelve patients ( 2 female) were included in the final experiment. The mean time since stroke was 28 months (range 4-104). Patient characteristics are listed in Table 1. Structural brain images with markers of the lesion sites are shown in supplemental Figure S1 (available at www.jneurosci.org as supplemental material).

\section{Clinical evaluation}

Patients were evaluated at the time of scanning using the nine-hole peg test (NHPT), Motricity index (MI), and action research arm test (ARAT) (Table 2). The NHPT measures the time taken to place nine pegs consec-

\section{Table 2. Clinical scores}

\begin{tabular}{lllc}
\hline Patient & NHPT (\%) & ARAT (\%) & MI-UL (\%) \\
\hline 1 & 92.4 & 55 & 100 \\
2 & 60.6 & 57 & 100 \\
3 & 68.1 & 57 & 100 \\
4 & 43.0 & 36 & 89 \\
5 & 85.7 & 57 & 100 \\
6 & 68.3 & 55 & 81 \\
7 & 69.7 & 51 & 100 \\
8 & 70.5 & 55 & 100 \\
9 & 38.6 & 56 & 77 \\
10 & 0 & 15 & 56 \\
11 & 76.3 & 57 & 100 \\
12 & 5.0 & 25 & 77 \\
Mean \pm STD & $56.5 \pm 29.5$ & $48 \pm 14.5$ & $90 \pm 14.4$ \\
\hline
\end{tabular}

Affected limb scores as a percentage of unaffected limb scores. UL, Upper limb.

utively into individual holes, using one hand (Heller et al., 1987). If the task was not completed within a minute then the number of pegs placed within that time was scored. Each hand was examined three times and the mean score recorded as pegs per second for that hand. The NHPT score is expressed as the percentage of pegs per second for the affected hand with respect to the unaffected hand. The MI reflects a clinical assessment of power in three muscle groups of the upper limb. In the ARAT, patients are asked to manipulate objects of varying sizes with the affected arm, assessing four aspects of arm function (grasp, grip, pinch movements, and gross arm movements). Each patient's clinical picture was dominated by motor impairment with little or no sensory loss. The Ashworth scale for spasticity was zero in all patients. To obtain an overall index of residual motor function that is less affected by floor or ceiling effects that may arise when only taking one score into account, we derived a combined clinical score, using the first principal component of a principal component analysis of the clinical assessment scores, as described previously (Ward et al., 2003a,b). In the resulting combined score, a positive score denotes better residual function whereas a negative score denotes poorer residual function.

\section{Interhemispheric contralesional PMd-ipsilesional M1}

paired-coil TMS

In addition to the clinical assessment, we sought to obtain a physiological measure of the integrity or pathology of cPMd influences on ipsilesional M1 (iM1) using paired-coil TMS (Civardi et al., 2001; Koch et al., 2006; O'Shea et al., 2007b; Mars et al., 2009). TMS was performed $1 \mathrm{~d}$ after the scanning session (see below) using two MAGSTIM 200 stimulators (Magstim). We measured resting motor threshold (rMT) and active motor threshold (aMT) for each hemisphere and interhemispheric influences from cPMd to iM1 (cPMd-iM1) using a previously described protocol (Mochizuki et al., 2004). This physiological measure was acquired at rest only because during voluntary action, I-waves in motor 
cortex are recruited differently than at rest (Amassian and Stewart, 2003). This would make it difficult to ascertain whether any stroke-related changes in motor-evoked potentials (MEPs) in an active setting were caused by a change in I-wave recruitment or the stimulation of different intracortical pathways. Here, we were primarily interested in obtaining a physiological measure (separate from the fMRI data) of cPMd influence on iM1 after stroke, assessing this patient-by-patient measure in relation to variability in residual motor function. Moreover, we tested how this measure related to differences found in brain responses during concurrent TMS-fMRI across our patient group, as explained below.

For motor threshold measurement, the handle of a $70 \mathrm{~mm}$ diameter, figure-of-eight coil was held pointing posterolaterally over the M1 hand representation, defined as the position at which stimulation produced consistent MEPs in the target first dorsal interosseous (FDI). rMTs were defined as the lowest stimulation intensity required to evoke an MEP in the relaxed FDI of $>50 \mathrm{mV}$ in 5 of 10 trials. aMTs were assessed during voluntary contraction of the target FDI at $\sim 10 \%$ of maximum force and defined as the lowest stimulus intensity required to evoke an MEP of $>200 \mathrm{mV}$ in 5 of 10 trials. For the paired-coil protocol probing the interhemispheric influence of cPMd on iM1, a small TMS coil (figureof-eight shape, $50 \mathrm{~mm}$ diameter) was placed over cPMd by locating it 2 $\mathrm{cm}$ anterior and $1 \mathrm{~cm}$ medial to the motor hotspot (for similar PMd coil locations, see Johansen-Berg et al., 2002; Bestmann et al., 2005, 2008b; O'Shea et al., 2007b; Schluter et al., 1998, 1999), with the handle pointing laterally for a medially directed, induced current (Mochizuki et al., 2004; Koch et al., 2006). A second coil (figure-of-eight shape, $70 \mathrm{~mm}$ wing diameter) was placed over the iM1 hand representation, as described for motor threshold measurement above. A conditioning stimulus (CST) was applied over cPMd $8 \mathrm{~ms}$ before a test stimulus (TS) was applied over iM1, with the latter initially set at $100 \%$ of rMT for the affected hand. The TS intensity over iM1 was then adjusted in each patient to evoke an unconditioned MEP in the FDI of the weak hand of $\sim 1 \mathrm{mV}$ amplitude. If it was not possible to obtain an MEP of this amplitude, the lowest intensity still producing a stable MEP was used. Conditioned trials (CST and TS) were randomly interleaved with unconditioned trials (TS alone) during the paired-coil protocol. A minimum of 15 trials of each condition was recorded. All MEPs in response to $\mathrm{iM1}$ pulses were recorded by surface EMG (using a belly-to-tendon montage) from the FDI of the weak hand. The raw signal was amplified and filtered with a bandpass filter of $30 \mathrm{~Hz}$ to $1 \mathrm{kHz}$ (Digitimer). Signals were digitized at $2 \mathrm{kHz}$ (CED Power1401, Cambridge Electronic Design) and stored on a laboratory computer for offline analysis.

\section{Concurrent TMS-fMRI}

Concurrent TMS-fMRI can provide insights about causal interactions among brain regions and help to establish causal brain-behavior relations for the human brain not only at the local site targeted with TMS, but also for remote interconnected brain regions (Sack, 2006; O'Shea et al., 2007a; Bestmann et al., 2008, Driver et al., 2009). Here we used this approach in a $2 \times 2$ factorial event-related design in which each trial consisted of an instruction to perform a single affected hand grip or to maintain rest, and a concurrent high- or low-intensity TMS over cPMd (at mean $79 \%$ or $44 \%$ of maximal stimulator output intensities, respectively; see below). TMS at these intensities was applied during hand grip or rest with equal probability.

Experimental paradigm. During scanning, a visual cue on each trial indicated that participants should either perform a single brief isometric hand grip with their affected hand or maintain rest. Hand grips were performed using an MR-compatible manipulandum consisting of two force transducers (FSG15N1A; Honeywell) situated between two molded plastic bars (width $6 \mathrm{~cm}$ ). Compression of the two bars by isometric hand-grip resulted in the generation of a differential voltage signal, linearly proportional to force exerted, which was fed into a signal conditioner (CED 1902; Cambridge Electronic Design). This signal was digitized (CED 1401; Cambridge Electronic Design) and fed into a computer running Cogent 2000 (http://www.vislab.ucl.ac.uk/cogent.php). The dynamic change in recorded signal was projected in real time onto a screen to give visual feedback to each participant, as a column for which the height varied linearly with change in voltage and hence with force

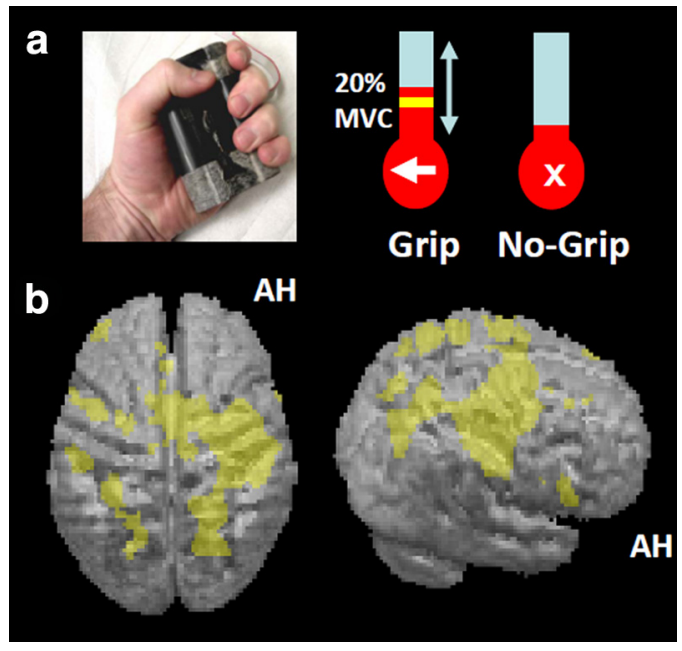

Figure 1. Experimental setup and main effects of the grip task. $\boldsymbol{a}$, Left, Photograph of gripforce manipulandum. Right, Screens displayed during scanning for a grip trial (arrow shown at bottom of thermometer-like visual display) and a no-grip trial (central cross being presented instead of the arrow). During grip trials, a yellow target bar indicated the required force level, as shown in the schematic example. The actual force exerted by the affected hand was indicated by red shading of the thermometer-like display and the white arrow pointed to the paretic hand to indicate that active grip was required. Participants were instructed to generate a nonballistic force matching the displayed target bar, using a gentle pace without major corrective movements (see main text). In all trials, TMS ( 5 pulses, $11 \mathrm{~Hz}$ ) was applied unpredictably to contralesional PMd at one of two intensities (110\% resting motor threshold or $70 \%$ active motor threshold) $900 \mathrm{~ms}$ after presentation of the force target level (or cross) visual instruction. $\boldsymbol{b}$, Hand grip-related activity, regardless of TMS. The results of the group random-effects analysis are projected onto the rendered averaged structural scans from all patients. The height threshold was set at $t>3.5$, uncorrected for multiple comparisons across whole brain, and the extent (or cluster) threshold set at $p<0.05$, corrected for multiple comparisons across the whole brain. AH, Affected hemisphere.

(Fig. 1). Before scanning, patients practiced the grip task (without TMS) for 3-5 min. They were also asked to perform the task before scanning but while lying in the scanner to further familiarize themselves with the task. During this time, we were able to observe any synergistic flexor movements (no mirror movements were observed, as also confirmed by the force-transducers; see below). In addition, subjects were asked to grip the manipulandum with maximum force to generate their maximum voluntary contraction (MVC).

At the start of each trial, the requirement for an active hand grip (if applicable) was indicated visually by an arrow pointing to the side of the affected hand, as displayed at the bottom of the screen for $3 \mathrm{~s}$ (Fig. 1a). The appearance of this arrow indicated that the subject was to perform a single brief handgrip with the affected hand, to be continued until the column representing the force applied came into contact with a horizontal bar on the screen (indicating the target force of $20 \%$ of the affected hand's MVC on the day of scanning), at which point the grip could be released. In an equal number of unpredictable intermingled trials, a cross was presented instead to indicate that subjects should maintain rest. In this case, participants kept their hands relaxed. Participants held one additional manipulandum in their unaffected hand to record any mirror movements or undesired twitches during TMS caused by a possible spread of excitation from the stimulated cPMd into adjacent contralesional M1 (cM1). With this setup, we confirmed outside of the main experiments that TMS-induced movements of the hand or fingers could indeed be detected reliably by the force transducers when TMS similar to our main stimulation protocol was applied to contralesional M1 instead of cPMd ( 5 pulses at $11 \mathrm{~Hz}$ and $110 \% \mathrm{rMT}$ ). No such movements were observed in the force recordings during TMS over $\mathrm{CPMd}$, demonstrating that contralesional M1 was not directly stimulated by the cPMd-TMS protocol applied during the main experiment.

In addition to the instruction to grip or rest during fMRI, as part of each event, TMS was applied to cPMd inside the scanner unpredictably at 
either $110 \%$ of individual $\mathrm{rMT}$ (TMS $_{\text {high }}$ condition) or $70 \%$ of aMT (TMS $_{\text {low }}$ condition) on each trial. Resting MT during scanning had been determined visually for the unaffected hand when stimulating over contralesional M1. Thresholds were defined as the stimulator output that elicited clearly visible responses in the FDI in five of 10 trials, with the hand either relaxed (rMT) or during a gentle finger pinch (aMT). Once established, this threshold was confirmed by reducing the intensity by $2 \%$ of maximum stimulator output (MSO) and repeating the procedure. When no further responses were observed, the intensity was increased in $2 \%$ MSO steps until a clear response became visible again. In the $\mathrm{TMS}_{\text {low }}$ condition, the actual stimulation intensity was around half (mean $44 \pm$ $7 \% \mathrm{SD}$ of MSO) of the level of the intensity in the $\mathrm{TMS}_{\text {high }}$ condition (mean $79 \pm 11 \% \mathrm{MSO}$ ). Therefore, $\mathrm{TMS}_{\text {high }}$ can be expected to exert significantly stronger effects on cortical processing (Bestmann et al., 2008) compared with $\mathrm{TMS}_{\text {low }}$. This was directly assessed by contrasting the two conditions in our event-related fMRI analysis (see below). Note that comparing high-intensity (effective) TMS to low-intensity TMS (less effective) can provide a better control for any potential nonspecific effects of TMS application (e.g., due to the click-sound associated with TMS delivery or anticipation of such delivery) than would be the case if merely comparing high-intensity TMS versus none. The two TMS intensities for the fMRI session differ somewhat in terms of absolute MSO from the motor threshold obtained separately outside the scanner. This is primarily because visually determined thresholds are slightly higher than motor thresholds determined using electromyography, and because of construction differences between the MR-compatible TMS coil and standard TMS coils.

Each TMS train during scanning comprised of five pulses at $11 \mathrm{~Hz}$, starting $900 \mathrm{~ms}$ [10 echo-planar imaging (EPI) slice acquisitions] after presentation of the instructional visual cue. Previous work in healthy subjects with an equivalent paradigm had shown that, with this interval, TMS-pulse application coincided well with the neural activity related to grip force generation (Bestmann et al., 2008b). A single scanning session was comprised of 100 trials (20 each of $\mathrm{TMS}_{\text {high }}$-grip, $\mathrm{TMS}_{\text {low }}$-grip, $\mathrm{TMS}_{\text {high }}$-rest, $\mathrm{TMS}_{\text {low }}$-rest, and null events). Each patient therefore received a total of 400 TMS pulses during the main experiment, in line with currently available safety recommendations (Rossi et al., 2009). The intertrial intervals varied unpredictably between 11 and $21 \mathrm{~s}$ (mean, 16.11 s). These conservatively long intertrial intervals were chosen to minimize carry-over effects between TMS trials with the stimulation used (Modugno et al., 2001; Gilio et al., 2007). However, we note that the TMS aspects of our design (high or low intensity) were event-related and had a pseudorandom order, so that any possible carry-over effects could not contribute to our specific contrasts in the fMRI analysis. Trial order was pseudorandomized so that each trial type occurred twice within 10 consecutive trials.

Patients were trained outside the scanner without TMS being applied until comfortable with the grip task. Inside the scanner, the TMS coil was positioned over cPMd. The task was briefly practiced again, ensuring that patients performed brief but nonballistic isometric hand grips that reached or approximated the required force level on every active trial with only the contralesional affected hand. We explicitly instructed patients that speed was not critical and that they should generate a nonballistic handgrip to approximately match the displayed target bar, using a gentle pace without major corrective movements (Bestmann et al., 2008b). These instructions ensured that patients could perform the task without difficulty and rendered it less likely that TMS would induce any systematic changes in behavior. The latter was important for our approach, and we therefore chose a simple nonspeeded motor task, which rendered it less likely for TMS to have any systematic behavioral consequences in the present paradigm, as also confirmed in our previous study on healthy participants (Bestmann et al., 2008).

A few trials were performed inside the scanner with TMS being applied to cPMd at $110 \%$ rMT of the affected hand while patients were contracting their unaffected hand (i.e., contralateral to TMS) at $\sim 20 \%$ MVC. This allowed a further check that indeed no twitches were induced by cPMd TMS (neither ipsilateral nor contralateral to the PMd). No overt muscle responses were observed in any participant, nor later reported by participants, other than the intended grip with the weak hand when required by the grip task.

Data acquisition. MRI was conducted with a 1.5T Magnetom Sonata system (Siemens Medical Solutions) operating with the standard CP receive head and body transmit coil. Whole-head T1-weighted structural anatomical images were acquired after the fMRI experiment using a three-dimensional modified driven equilibrium Fourier transform sequence with an isotropic resolution of $1 \mathrm{~mm}^{3}$ (Deichmann et al., 2004). During fMRI, functional T2*-weighted MRI transverse EPI with blood oxygenation level-dependent (BOLD) contrast were obtained using a multislice gradient echo EPI sequence with the following parameters: 848 volume acquisitions, 20 slices/volume, $64 \times 96$ matrix, $3 \times 3 \mathrm{~mm}$ inplane resolution with $50 \%$ oversampling in phase-encoding direction, $2.5 \mathrm{~mm}$ slice thickness plus $50 \%$ spatial gap between spatially adjacent slices, repetition time $=1800 \mathrm{~ms}$, echo time $=42 \mathrm{~ms}, \alpha=90^{\circ}$, echospacing $500 \mu \mathrm{s}, 2298 \mathrm{~Hz} /$ pixel bandwidth, trapezoidal readout gradients with a ramp of $130 \mu$ s and a flat top of $240 \mu$ s, field of view $=192 \times 192$ $\mathrm{mm}$, max slew rate $214.9 \mathrm{mT} / \mathrm{m} / \mathrm{ms}$. During scanning, any potential physiological or technical artifacts were constantly monitored online (Weiskopf et al., 2007). After each experimental session, whole brain coverage EPI volumes were acquired in the same orientation as for the actual experiment to facilitate spatial normalization of the spatially restricted functional image series.

Technical aspects of concurrent TMS-fMRI. TMS was implemented inside the scanner using a MagStim Rapid system (Magstim) with a custom-built, MR-compatible, nonferrous figure-of-eight stimulation coil [two windings with 10 turns each, inner wing diameter $53 \mathrm{~mm}$, distance between outer coil surface and windings of $2-3 \mathrm{~mm}$ (variation due to manufacturing tolerance); coil inductance, including cable, of 20 $\mu \mathrm{H}$; maximal current at $100 \%$ stimulator output of $\sim 5 \mathrm{kA}$ ). The stimulation unit was housed inside the scanner room in a shielded cabinet, from which the stimulation coil cable was fed through a custom filter box (Magstim). Residual radio frequency (RF) transmission along the coil cable was further suppressed using ferrite sleeves (Ruff et al., 2006; Bestmann et al., 2008b; Blankenburg et al., 2008). The TMS coil was connected to the stimulator in parallel to a high voltage relay-diode combination (Magstim ES9486; Magstim), eliminating residual leakage current flow through the TMS coil (Bestmann et al., 2008b; Weiskopf et al., 2009). The relay and TMS stimulator were controlled with a unit developed in-house based on a BASIC Stamp 2 micro-controller (Parallax). TMS pulses were applied during the dead time between the EPI navigator echoes and the EPI data readout, and separated from RF slice excitation pulses (Bestmann et al., 2003). Each slice coincided equally often with TMS pulses to avoid any systematic influences on slice-byslice variance. For a more detailed treatment of the technical aspects of concurrent TMS-fMRI, the reader is referred to previous work (Bohning et al., 1998; Shastri et al., 1999; Baudewig et al., 2000; Bestmann et al., 2003; Bungert et al., 2008a,b; Weiskopf et al., 2009).

Visual stimulation, grip-force data acquisition, TMS triggering and intensity regulation, and relay settings were controlled using the toolbox Cogent 2000 (http://www.vislab.ucl.ac.uk/cogent.php) running under Matlab (Mathworks). Foam-padded cushions were used to restrict head movement. Participants wore earplugs (single number rating $=36 \mathrm{~dB}$ ) and headphones to reduce acoustic noise from the scanner and the TMS discharge sound. Inside the scanner, the TMS coil was positioned over cPMd using an MR-compatible custom-built coil holder. The cPMd was located as in the paired-coil experiment, at the point $2 \mathrm{~cm}$ anterior and 1 $\mathrm{cm}$ medial to the motor hotspot (Johansen-Berg et al., 2002; Bestmann et al., 2005, 2008b; O'Shea et al., 2007b; Schluter et al., 1998, 1999), and marked on the subject's scalp. The TMS coil was oriented tangential to the scalp, approximately perpendicular to the precentral sulcus. This induced a biphasic current with an initial anteroposterior-induced direction relative to the axis of the coil. Following scanning, the cPMd site that had been stimulated inside the scanner was reconstructed from T1weighted structural scans, which included five fiducial markers placed at the center of the two TMS coil wings, their anterior bifurcation, and the left and right side of the coil cable at their posterior bifurcation (supplemental Fig. S2, available at www.jneurosci.org as supplemental material). The stimulation site was thereby determined as the intersection between 
Table 3. TMS parameters for each patient

\begin{tabular}{|c|c|c|c|c|c|}
\hline \multirow[b]{2}{*}{ Patient } & \multicolumn{4}{|c|}{ Absolute motor threshold (\% MSO) } & \multirow{2}{*}{$\begin{array}{l}\text { (PMd-iM1 connectivit) } \\
\text { - measure (\% } \\
\text { unconditioned MEP) }\end{array}$} \\
\hline & $\mathrm{rMT}_{\mathrm{AH}}$ & $\mathrm{aMT}_{\mathrm{AH}}$ & $\mathrm{rMT}_{\mathrm{UH}}$ & $\mathrm{aMT}_{U H}$ & \\
\hline 1 & 55 & 47 & 48 & 45 & 68.9 \\
\hline 2 & 55 & 42 & 38 & 31 & 65.4 \\
\hline 3 & 40 & 34 & 41 & 37 & 106.3 \\
\hline 4 & 52 & 32 & 37 & 22 & 120.6 \\
\hline 5 & 51 & 43 & 45 & 37 & 105.9 \\
\hline 6 & 41 & 29 & 40 & 28 & 61.6 \\
\hline 7 & 40 & 35 & 37 & 32 & 104.4 \\
\hline 8 & 42 & 40 & 46 & 38 & 91.5 \\
\hline 9 & 60 & 40 & 52 & 36 & 103.8 \\
\hline 10 & 82 & 60 & 50 & 39 & 118.1 \\
\hline 11 & 65 & 44 & 44 & 30 & 65.0 \\
\hline 12 & 100 & 93 & 52 & 38 & 122.4 \\
\hline Mean \pm STD & $56.9 \pm 18.2$ & $44.9 \pm 17.1$ & $44.1 \pm 5.6$ & $34.4 \pm 6.1$ & $94.5 \pm 23.2$ \\
\hline
\end{tabular}

AH, Affected hemisphere; UH, unaffected hemisphere.

the imaged cortex and a line going through the center of the TMS coil and perpendicular to the plane of the figure-of-eight coil. The reconstructed TMS coil position for each participant confirmed that the stimulation location was clustered within cPMd anterior to the precentral gyrus, and dorsal to the intersection of the medial frontal sulcus and precentral sulcus (supplemental Fig. S2, available at www.jneurosci.org as supplemental material) (Amiez et al., 2006).

\section{Data analyses}

Behavioral data during fMRI. Movement onset, grip duration, and peak force were measured for each trial. Movement onset was defined as the latency between cue onset and the point at which grip force exceeded $20 \%$ of baseline value. Note that cortical activity related to grip force production started several tens or hundreds of milliseconds before this level was reached. Together with the TMS train duration of $360 \mathrm{~ms}$, this ensured that cPMd stimulation would overlap with grip-related activity during grip trials (Bestmann et al., 2008b). Grip duration was determined as the interval between the successive time points at which grip force started to exceed or started to fall below the 20\%-of-baseline boundary on each trial. The peak force was determined as the maximum force during this period for each trial. Paired two-tailed $t$ tests were used to compare these parameters between high and low TMS intensity conditions across participants. Our explicit aim was to use TMS during scanning to probe local and remote BOLD signal changes (Baudewig et al., 2001; Bestmann et al., 2004, 2008a) rather than to produce behavioral changes that might then complicate interpretation of any fMRI changes also associated with TMS. Consequently, our instructions did not require patients to perform the movements at high speed or accuracy (for a closely analogous approach in healthy participants, see Bestmann et al., 2008b), and we therefore did not a priori expect any TMS impact on performance in the grip task. Instead we were specifically interested in how cPMd TMS might impact on brain activity in remote brain areas that cPMd may influence.

Interhemispheric cPMd influence on iM1, as assessed with paired-coil TMS. Individual trials were examined offline and those showing any voluntary EMG activity were discarded (18.1\% of trials in total). Peakto-peak MEP amplitudes were measured in the remaining trials using in-house software. The influence of cPMd on iM1 was calculated in each patient as the mean amplitude of conditioned MEPs expressed as a percentage of unconditioned MEPs. The relevant TMS parameters are shown in Table 3. We first assessed the correlation between the pairedcoil cPMd-iM1 measure and the combined clinical score. However, more impaired patients often required higher test pulse intensities to elicit any MEP, due to greater resting motor thresholds in the affected hemisphere (Table 3). Therefore, we controlled for floor or ceiling effects due to changes in motor thresholds or difficulties in evoking MEPs of $1 \mathrm{mV}$ amplitude in some patients. For this we used a partial correlation procedure, in which we included resting motor thresholds in the affected hemisphere as well as the size of the motor-evoked potential elicited by the test pulse.
One might expect that any pathologies in excitability of connections between $\mathrm{CPMd}$ and iM1 may be more pronounced when patients with less residual motor functions have to make a movement. However, this is difficult to quantify directly with paired-coil TMS, because the recruitment of I-waves cannot easily be compared during voluntary action and rest (Amassian and Stewart, 2003). To study the impact of having to make a movement with the paretic hand, we therefore chose instead to exploit the concurrent TMS-fMRI technique that enabled us to measure influences from cPMd TMS on BOLD signals from other (ipsilesional and contralesional) motor regions both during rest and voluntary action, relating this to the physiological paired-coil TMS measure that we were able to obtain in the separate experiment.

fMRI analysis. EPI images were reconstructed offline (Josephs et al., 2000 ) and the first five volumes discarded to allow for $T_{1}$ equilibration effects. All EPI slices coinciding with TMS pulses were identified. In addition, all slices in which the magnitude of their difference in mean signal intensity to the anatomically corresponding slice in the previous image volume exceeded $3 \mathrm{SD}$ from mean slice difference in the time series $(0.12 \%$ of all slices $)$ were replaced by the mean of the spatially equivalent slices from the previous and the subsequent image volume (Ruff et al., 2006; Bestmann et al., 2008). Final inspection was accomplished using the ArtRepair toolbox implemented in SPM5. Functional imaging data were analyzed using Statistical Parametric Mapping (SPM5, http://www.fil.ion.ucl.ac.uk/spm) implemented in Matlab 7. Realignment to the first volume corrected for any interscan head movements. Interactions of head motion with geometric distortions were accounted for using the unwarp toolbox as implemented in SPM5 (Andersson et al., 2001). Additional preprocessing included detrending of time series in each voxel with a linear model of the global signal (Macey et al., 2004) and an $\mathrm{AR}(1)$ model to account for serial autocorrelations in the data.

The resulting images were spatially normalized to a standard EPI template based on the Montreal Neurological Institute (MNI) reference brain in Talairach space (MNI305 brain), using fourth-degree B-spline interpolation, and resampled to a $3 \times 3 \times 3 \mathrm{~mm}^{3}$ voxel size. Spatial normalization parameters were estimated from the whole-brain EPI images and the respective normalization transformation was then applied to the EPI images of the main experimental session. We checked to confirm that normalization did not introduce any anomalies in the images of our brain-damaged patients. We noted that all of the lesions were subcortical, whereas (as described above) the most critical fMRI results were cortical, arising well away from the damaged regions. The resulting images were smoothed with an isotropic $9 \mathrm{~mm}$ full-width at half-maximum Gaussian kernel to allow for valid statistical inference according to Gaussian random field theory, in accordance with the standard SPM approach. Any potential remaining artifacts related to head motion or other nonphysiological signals were then removed using automatic independent component analysis-based denoising (Tohka et al., 2008). To allow a unified statistical model, images from the only two patients with a left-hemispheric lesion were flipped about the sagittal plane to permit statistical comparison across participants, i.e., shifting the ipsilesional hemisphere to the right for all cases (Ward et al., 2003b, 2006, 2007).

Statistical analysis of the fMRI data involved two stages. First, a single subject fixed-effects model was computed for each participant by multiple regression of the voxelwise time series onto a composite model containing the covariates of interest. Each of the four event-related trial types (TMS $_{\text {high }}$ during grip, or $\mathrm{TMS}_{\text {low }}$ during grip, $\mathrm{TMS}_{\text {high }}$ during rest, and $\mathrm{TMS}_{\text {low }}$ during rest) were modeled as delta functions, with onsets defined as the first TMS pulse, and were included as separate covariates. To account for any additional variance induced by any slight trial-bytrial and/or intersubject variation in grip onset, grip duration, or grip force, these parameters were included as parametric modulations that scaled the delta function representing the onset of each grip trial.

All covariates were convolved with a canonical synthetic hemodynamic response function in a general linear model (Friston et al., 1994, 1998), together with a single covariate representing the mean (constant) term over scans. The parameter estimates for each covariate resulting from the restricted maximum-likelihood fit of the model to the data were calculated. Statistical parametric maps of the $t$ statistic resulting from linear contrasts of covariates (Friston et al., 1994) were generated and 
stored as separate images for each subject. First, for each subject we calculated the effect of grip minus rest (regardless of TMS intensity), the effect of high- minus low-intensity TMS to cPMd (regardless of whether gripping or not), and the two-way interactions between these factors. Second, the group level random-effects analysis comprised parameter estimates for each of these contrasts across all subjects. Contrast images from each subject were entered into a one sample $t$ test for each contrast of interest. The height threshold for the resulting $\operatorname{SPM}(t)$ s was set at $t>$ 3.5 , and the extent (or cluster) threshold set at $p<0.05$, corrected for multiple comparisons across the whole brain.

To exploit heterogeneity in our patient group, we tested whether any between-subject variability in these TMS-fMRI effects related to the degree of residual motor function, as indexed by our combined clinical assessment score for each patient. In addition, we were interested in whether the degree of interhemispheric influence from cPMd to ipsilesional primary motor cortex (as assessed with our separate paired-coil cPMd-iM1 physiological measure) could explain any additional variability in our concurrent TMS-fMRI results. We therefore performed a linear regression analyses within SPM5 using the contrast images for each subject, with the effects of interest now being regressed upon separate values representing the degree of residual function as assessed by the composite clinical score, and (separately) the paired-coil cPMd-iM1 measure for each subject. We first considered the combined clinical score because

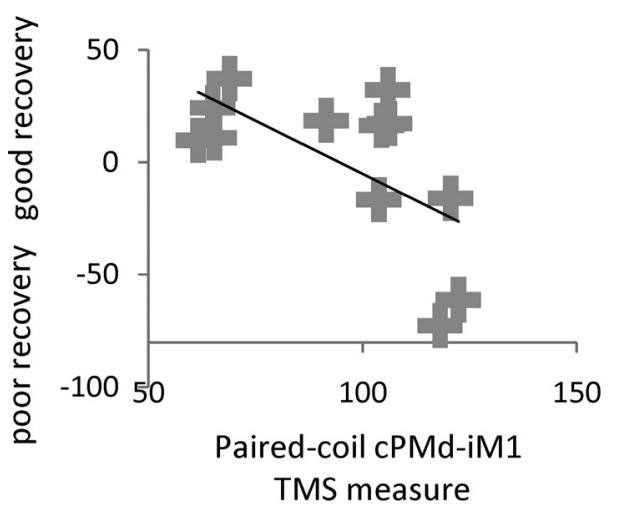

\% MEP suppression \% MEP facilitation

Figure 2. Scatterplot showing the correlation, with regression line, between the combined clinical score and the interhemispheric CPMd-iM1 influence measured with paired-coil TMS (conditioned MEP/unconditioned MEP as a percentage) in each patient. For the combined clinical score (along the $y$-axis), a higher value indicates better residual motor function. This measure correlated with the value of the interhemispheric CPMd-iM1 influence shown along the $x$-axis; a better motor recovery was associated with a physiological inhibitory effect, whereas poorer recovery was associated with less interhemispheric inhibition or even facilitation (i.e., paired-coil effects of $>100 \%$, as for the rightmost cases). previous work has shown some relation between brain activity during hand grip and to residual motor function (Ward, 2006). We then considered the cPMd-iM1 measure to see if any additional fMRI variance might be explained by this further physiological measure of interhemispheric influence.

To illustrate the relationship for significant peak voxels, we plotted the extracted parameter estimates from the peak voxels against the combined clinical score and separately against the paired-coil cPMd-iM1 measure. We note that this is merely to provide some visualization of the relationship between the variables tested. The formal analysis to address this was performed via the SPM linear regression analysis and associated statistics.

\section{Results}

\section{Behavioral results during scanning}

All patients were able to perform the grip task adequately (supplemental Fig. S3, available at www.jneurosci.org as supplemental material). No patient displayed mirror movements in unaffected hand or synergistic flexor movements in more proximal joints, when assessed outside the scanner by direct observation or during scanning, as confirmed by inspection of the sensitive force recordings from the unaffected hand during movement of the affected hand. The grip onset times (mean \pm $\mathrm{STD}, 1.3 \pm 0.19 \mathrm{~s}$ for $\mathrm{TMS}_{\text {low }} ; 1.28 \pm 0.2 \mathrm{~s}$ for $\mathrm{TMS}_{\text {high }}$ ) indicate that TMS overlapped with neural processes associated with active grip generation, as in our recent TMS-fMRI study of healthy subjects in an equivalent paradigm (Bestmann et al., 2008b). The comparison of task performance between the $\mathrm{TMS}_{\mathrm{high}}$ and $\mathrm{TMS}_{\text {low }}$ conditions was not significantly different for any grip parameter (grip onset, $t_{(11)}=0.92$; grip duration, $t_{(11)}=0.90$; peak force, $t_{(11)}=1.82$ ). Thus, high-intensity TMS during scanning did not significantly change motor behavior compared with low-intensity TMS, consistent with our intention of avoiding any significant behavioral effects of the TMS manipulation during scanning that might otherwise have complicated interpretation of TMS influences for high versus low intensity in the fMRI data (Bestmann et al., 2008b; Ruff et al., 2006).

We were specifically interested in examining any variability in the causal influence of cPMd TMS on surviving brain regions (as assessed with $\mathrm{PMRI}$ BOLD signal changes) as a function of residual upper limb impairment (as assessed by a composite clinical score) and the physiological influence of cPMd on iM1 (as assessed separately using paired-coil TMS). In the results below, we first report the results from the cPMd-iM1 paired-coil TMS experiment and then report their use as an explanatory variable for the fMRI data.

Table 4. SPM main effect of grip versus rest (irrespective of TMS) and main effect of TMS high versus low TMS (irrespective of grip)

\begin{tabular}{|c|c|c|c|c|c|c|}
\hline \multirow[b]{2}{*}{ Anatomical region } & \multirow[b]{2}{*}{ Side } & \multicolumn{3}{|c|}{ Talairach coordinates in MNI space } & \multirow[b]{2}{*}{ Maximum Z score } & \multirow[b]{2}{*}{ Cluster $p$ value } \\
\hline & & $x$ & $y$ & $Z$ & & \\
\hline \multicolumn{7}{|c|}{ Main effect of grip versus rest (irrespective of TMS) } \\
\hline Postcentral gyrus & $\mathrm{i}$ & 48 & -24 & 35 & 4.72 & $<0.001$ \\
\hline Supplementary motor area & & 3 & -6 & 69 & 4.62 & \\
\hline Dorsal premotor cortex & & 30 & -15 & 72 & 4.22 & \\
\hline Inferior frontal gyrus & $c$ & -51 & 6 & 27 & 4.26 & $<0.05$ \\
\hline Superior parietal lobule & i & 24 & -60 & 57 & 4.60 & $<0.001$ \\
\hline Superior parietal lobule & $c$ & -33 & -48 & 60 & 5.01 & $<0.001$ \\
\hline Inferior frontal gyrus & i & 63 & 12 & 18 & 3.69 & $<0.05$ \\
\hline Dorsal premotor cortex & $c$ & -24 & -12 & 63 & 3.89 & $<0.05$ \\
\hline Ventral premotor cortex & $C$ & -45 & 0 & 57 & 3.84 & $<0.05$ \\
\hline \multicolumn{7}{|c|}{ Main effect of TMS high versus low (irrespective of TMS) } \\
\hline Rolandic operculum & i & 51 & -24 & 21 & 3.80 & $<0.05$ \\
\hline Superior temporal gyrus & $c$ & -54 & -30 & 12 & 3.92 & $<0.05$ \\
\hline Middle cingulate cortex & $C$ & -3 & 9 & 39 & 3.71 & $<0.05$ \\
\hline
\end{tabular}

Height threshold of $t>3.5$, uncorrected for multiple comparisons across whole brain, and extent (or cluster) threshold set at $p<0.05$, corrected for multiple comparisons across whole brain. i, Ipsilesional; $c$, contralesional. 


\section{Interhemispheric paired coil TMS}

We measured the influence of cPMd on iM1 using paired-pulse TMS outside the scanner in a separate session. We found that the influence from $\mathrm{CPMd}$ on $\mathrm{iM} 1$ at rest was inhibitory (with the conditioning cPMd pulse reducing the MEP evoked by the iM1 test pulse) in some patients, similar to healthy controls (Mochizuki et al., 2004). But notably, in other patients, the conditioning stimulus to cPMd resulted in less inhibition or even facilitation (Table 3; Fig. 2). This finding was related to the combined clinical score $(r=-0.62, p<$ $0.05)$. Thus, in patients with minimal motor impairment, interactions between cPMd and iM1 at rest were predominantly inhibitory, similar to those previously observed in healthy subjects (Mochizuki et al., 2004; Koch et al., 2006; O'Shea et al., 2007). In contrast, in patients with greater impairment, this influence tended to be reversed, demonstrating that the paired-coil TMS approach can highlight impairment-specific differences in the influence of cPMd on iM1.

It is unlikely that our paired-coil TMS result can be explained by differences in rMTs or MEP size, as follows: (1) resting motor thresholds from either hemisphere did not correlate with the paired-coil PMd-M1 measure $\left[\mathrm{rMT}_{\text {affected hemisphere: }}\right.$ $r=0.36, p=0.25$, not significant; $\mathrm{rMT}_{\text {unaffected hemisphere }}: r=$ $0.25, p=0.43$, not significant]; (2) the partial correlation of the paired-coil cPMd-iM1 measure with the combined clinical score remained significant even after accounting for $\mathrm{rMT}_{\text {affected hemispere }}$ and test pulse MEP size $(r=-0.55, p<0.05)$; (3) mean MEP amplitudes for test pulses were not significantly different from the desired $1 \mathrm{mV}$ peak-to-peak amplitude (one-sample $t$ test, $t_{(11)}$ $=-1.43 ; p=0.18)$, thus ruling out systematic floor or ceiling effects that might otherwise have prevented us from detecting significant inhibition or facilitation.

\section{Relation between concurrent}

\section{TMS-fMRI results and combined clinical score}

In a separate experiment, we assessed the state-dependent influence of cPMd TMS on brain regions in either hemisphere that were activated by hand-grip with the paretic hand. First, we assessed the effects of the grip task performed with the affected hand (Fig. $1 b$; Table 4 ). As expected, relative activity increases during grip with the affected hand compared with rest (regardless of TMS intensity) were seen in ipsilesional sensorimotor cortex (including precentral and postcentral sulcus and extending into dorsal premotor cortex), caudal inferior frontal gyrus, bilateral middle cingulate cortex, and supplementary motor area, plus superior parietal lobule and dorsal and ventral premotor cortex, including the putative stimulation site in cPMd. Grip-related activity varied across our patient group. Those with greater impairment of the paretic hand (i.e., lower clinical scores) exhibited more activity during hand grip in secondary motor areas, consistent with previous observations (Ward et al., 2003a,b). The magnitude of brain activity during affected hand grip correlated negatively with the combined clinical score in ipsilesional PMd (peak $x=39, y=-12, z=51, z$-score $=4.68)$, supplementary motor area $(x=3, y=0, z=54, z$-score $=3.75)$, and contralesional PMd/M1 ( $x=-39, y=-6, z=48, z$-score 3.67) (Fig. 3). Importantly for interpretation of our later results, we also noted a progressive posterior shift in the peak of sensorimotor cortex activation with increasing motor impairment $(r=0.59, p=$ 0.043) (Fig. 4), as previously described (Rossini et al., 1998; Pineiro et al., 2001; Cramer, 2004; Cramer and Crafton, 2006).

Second, we compared all events with high-intensity TMS to those with low-intensity TMS, finding relative increases in BOLD signal in middle cingulate cortex as well as auditory cortex bilaterally, presumably because of the somewhat louder click associated with higher intensity TMS (Table 4) (Hanakawa et al., 2009; Siebner et al., 1999; Bestmann et al., 2004; Baudewig et al., 2001; Bohning et al., 1998).

Third, we examined the critical interaction of TMS intensity and motor state (i.e., hand grip vs rest) using the contrast $\mathrm{TMS}_{\text {high }}$ (grip-rest) $>\mathrm{TMS}_{\text {low }}$ (grip-rest). The resulting voxelwise parameter estimates from this contrast reflect the magnitude of the influence of the stimulated cPMd on other brain regions during hand grip compared with rest. For instance, if cPMd has no influence over region A then there will be no difference between grip minus rest for the high- versus low-intensity TMS conditions in the voxels corresponding to region A. If, however, there is an influence of cPMd TMS on region A that increases during hand grip then the high-intensity TMS condition will lead to a local increase in BOLD signal in region A during hand-grip, and thus the interaction contrast $\mathrm{TMS}_{\text {high }}$ (grip-rest) $>\mathrm{TMS}_{\text {high }}$ (griprest) will be positive. Although we found no consistent effects for the patient group on average, based on previous work (Ward et al., 2003a,b), our expectation was to find variability in relation to 


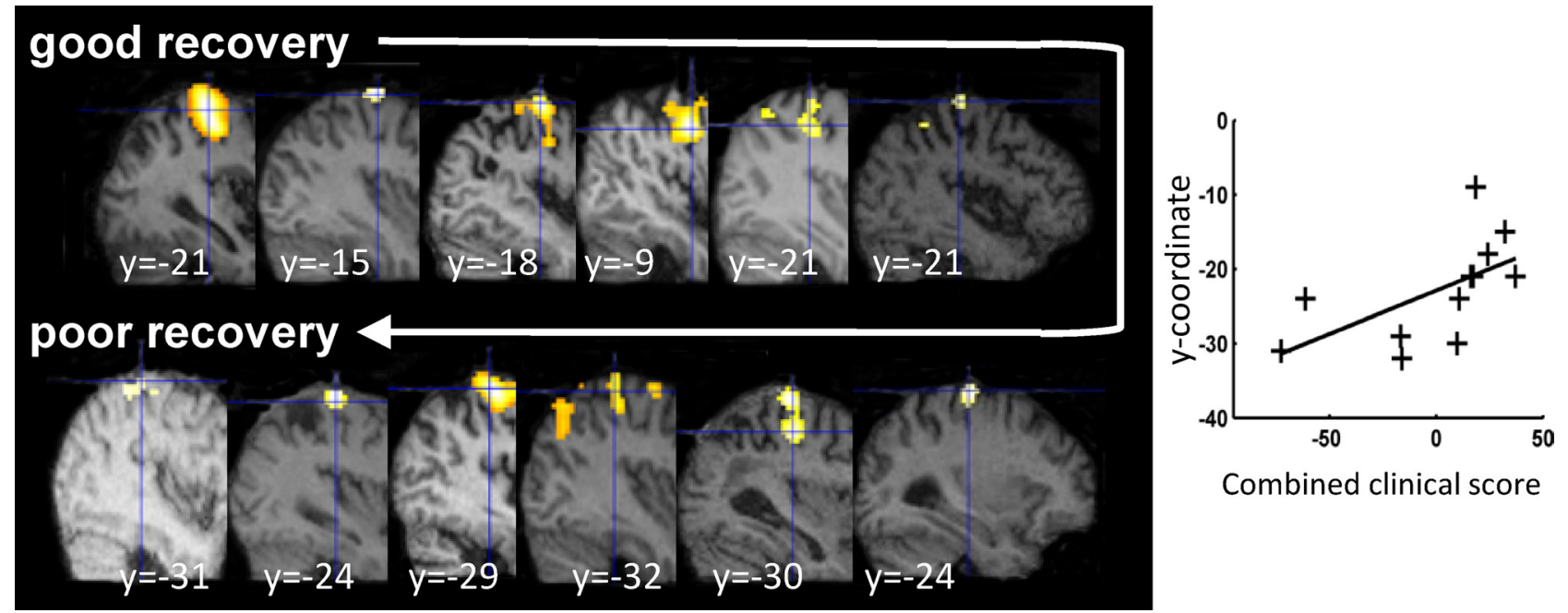

Figure 4. Relationship between the ipsilesional peak hand grip-related signal change and the combined clinical score. The SPM for the main effect of hand grip is overlaid on the individual structural scan of each patient. A posterior shift of activity in ipsilesional cortex was observed, with less well recovered patients exhibiting progressively more posterior peak activity. The $y$-coordinate from each individual patient for the peak activity for the main effect of grip versus rest (shown along the $y$-axis) is plotted against the combined clinical score from each patient (along the $x$-axis).

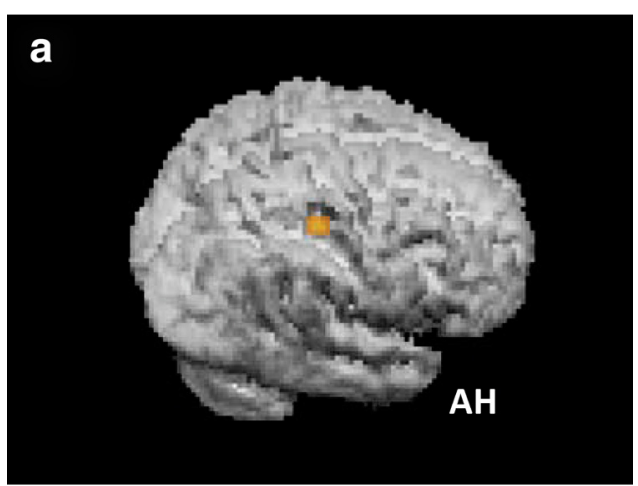

b

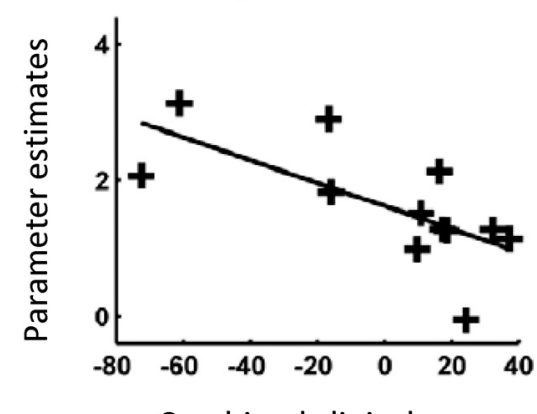

Combined clinical score

Figure 5. a, The facilitatory influence of contralesional PMd during hand grip (as measured with concurrent TMS-fMRI) correlated with combined clinical score in this ipsilesional cluster extending across posterior sensorimotor cortical regions. $\boldsymbol{b}$, SPM for the interaction term $\mathrm{TMS}_{\text {high }}$ (grip-rest) $>\mathrm{TMS}_{\text {low }}$ (grip-rest) overlaid on the rendered mean structural scan from all patients. The influence of CPMd on this cluster [assessed by the parameter estimates for $\mathrm{TMS}_{\text {high }}$ (grip-rest) $>\mathrm{TMS}_{\text {low }}$ (grip-rest)] are plotted against the combined clinical score for each patient. AH, Affected hemisphere.

the degree of impairment. We therefore tested whether the influence of cPMd TMS on other brain regions [a more facilitatory influence being reflected in a higher value for the contrast $\mathrm{TMS}_{\text {high }}$ (grip-rest) $>\mathrm{TMS}_{\text {high }}$ (grip-rest)] correlated with the combined clinical score for each patient (lower value reflecting greater motor impairment). We found that in our patients with greater clinical impairment, there was a more facilitatory effect of cPMd on only one region in the ipsilesional hemisphere. The most significant voxel was posterior and ventral to ipsilesional hand area of M1 (peak at $x=51, y=-30, z=42$ ) (Fig. 5). At a lower threshold ( $p<0.005$ ), the significant cluster extended between $y=-18$ and -38 in the anterior-posterior direction and between $z=38$ and 58 in the dorsal-ventral direction, overlapping greatly with the sensorimotor cortex activation seen in our patients for the grip task overall. We consider this region to be part of the sensorimotor cortex in our patients, particularly since we have already observed that hand grip-related activity was located progressively more posteriorly in our more impaired patients (Fig. 4). Contralesional PMd TMS did not exert a significant influence on any other brain region during hand grip compared with rest, neither on average nor when correlated with impairment. No effects in hand grip-related regions were observed for the negative interaction (i.e., the reverse SPM contrast).

Relation between concurrent TMS-fMRI results and separate interhemispheric paired-coil TMS physiological results We were also specifically interested in how patient-by-patient variability in our TMS paired-coil cPMd-iM1 measure may explain any variability in our fMRI results, over and above variability already explained by the main effect of hand grip and the $\mathrm{TMS}_{\text {high }}$ (grip-rest) $>\mathrm{TMS}_{\text {low }}$ (grip-rest) interaction. We found that a less inhibitory/more facilitatory influence of cPMd on iM1 in the paired-coil TMS experiment correlated positively with the magnitude of BOLD signal changes during hand grip (regardless of TMS intensity) in cPMd $(x=-30, y=-12, z=63, z$-score $=$ $3.98, p<0.05$ ) (Fig. 6). Second, the TMS paired-coil cPMd-iM1 measure correlated positively with the parameter estimates from the $\mathrm{TMS}_{\text {high }}$ (grip-rest) $>\mathrm{TMS}_{\text {low }}$ (grip-rest) interaction in only one region, ipsilesional inferior central sulcus $(x=36, y=-12$, $z=45$ ) corresponding to Brodmann area $4 \mathrm{p}$, the posterior part of primary motor cortex (Fig. 7). Thus patients with more pathological cPMd-iM1 paired-coil results showed stronger interaction effects of cPMd TMS in this posterior ipsilesional motor region.

For completeness, in an additional analysis we also looked for any age-dependent changes in motor function by additionally 


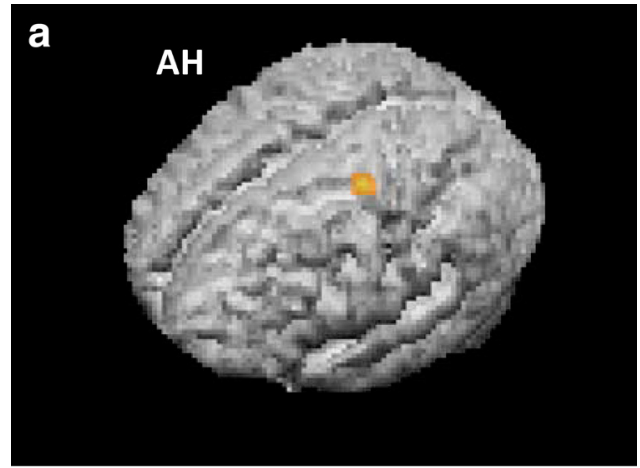

b

$x, y, z:-30-1263$

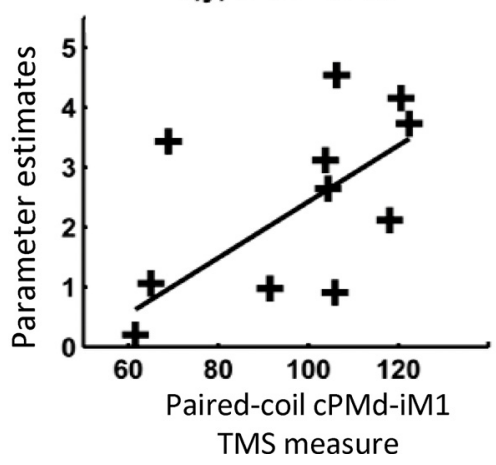

Figure 6. a, CPMd-iM1 interhemispheric influences at rest (as revealed by paired-coil TMS) correlated with hand grip-related activity in contralesional premotor cortex. Hand grip-related activity at the identified stimulation site in CPMd correlated with the separately measured interhemispheric paired-coil cPMd-iM1 influence $(p<0.05$, corrected, for multiple comparisons across the brain). The SPM for this effect is projected onto the rendered, average, normalized, $\mathrm{T}_{1}$-weighted structural image from all participants. $\boldsymbol{b}$, Parameter estimates for the main effect of hand grip minus rest (shown along the $y$-axis) are plotted in a patient-by-patient manner against the interhemispheric CPMd-iM1 influence (along the $x$-axis) are shown in the inlay. AH, Affected hemisphere.

including age as covariates of no interest at the second level of analysis. No influences of age or time-after-stroke were observed for the critical contrasts in any hand grip-related areas (data not shown).

\section{Discussion}

Contralesional PMd is thought to contribute to the support of recovered motor function after stroke, more so in patients with greater impairment (Johansen-Berg et al., 2002; Lotze et al., 2006; Ward et al., 2007), but the mechanism by which it exerts this influence has remained unknown. Work in primates has demonstrated that direct descending projections from secondary motor regions, including $\mathrm{PMd}$, have longer latencies and are weaker than those from M1 (Boudrias et al., 2010), suggesting additional synapses in the anatomical pathway for their actions on motoneurons. The descending motor pathway from PMd could involve the intermediate zone of the spinal cord or even propriospinal premotoneurons (Mazevet et al., 2003; Stinear and Byblow, 2004), which receive projections from premotor cortex, at least in nonhuman primates (Benecke et al., 1991). PMd is also reciprocally connected with ipsilateral (Lu et al., 1994; Wise et al., 1997; Dum and Strick, 2005) and contralateral (Marconi et al., 2003) cortical motor areas, including M1. An alternative route though which cPMd can influence residual motor function might thus be via corticocortical pathways. Our results provide evidence that in patients with more impairment, cPMd exerts an increasing influence on surviving sensorimotor cortex in the ip-

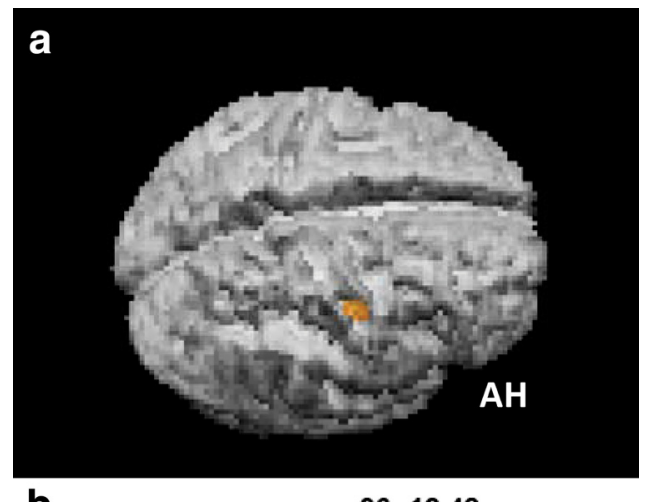

b $x, y, z: 36-1248$

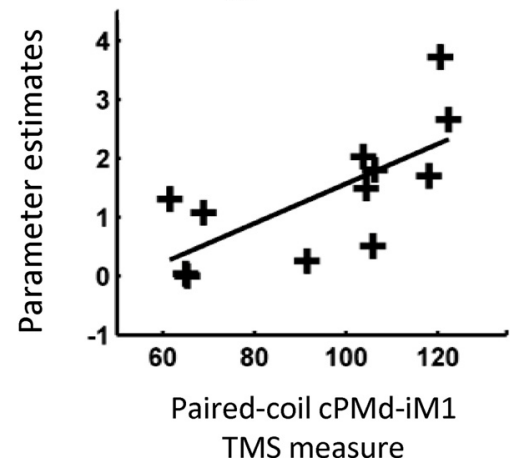

Figure 7. Brain regions in which the influence of CPMd during hand grip (as measured with concurrent TMS-fMRI) was greater when (PMd had a less inhibitory/more facilitatory affect on ipsilesional M1 (as measured with paired-coil TMS). $\boldsymbol{a}$, The SPM for the correlation seen in ipsilesional posterior central sulcus, BA4p, is overlaid on the rendered mean structural scan from all patients. $\boldsymbol{b}$, Each patient's parameter estimate for the interaction term TMS ${ }_{\text {high }}$ (griprest) $>$ TMS $_{\text {low }}$ (grip-rest) in ipsilesional posterior central sulcus, BA4p, plotted against the paired-coil measure of the interhemispheric cPMd-iM1 influence. AH, Affected hemisphere.

silesional hemisphere. We did not find any evidence for correspondingly increased influences on any other brain regions, including other secondary motor areas.

In the current experiments, across our group of stroke patients, variations in the influence of cPMd on surviving brain regions relate not only to clinical motor scores, but also to separate neurophysiological (paired-pulse TMS) markers of interhemispheric interactions. The magnitude of the influence of cPMd TMS upon BOLD signal in a posterior part of the ipsilesional sensorimotor cortical region was greater in those patients with more clinical motor impairment. Since clinical scores may not capture all of the important variability between patients (Talelli et al., 2008), we additionally used an independent physiological (paired-pulse) measure of cPMd-iM1 influence to further interrogate our fMRI results. We found that a significant proportion of the variability in the influence of cPMd TMS on BOLD signal in another ipsilesional posterior sensorimotor region, BA4p, was accounted for by this separate electrophysiological cPMd-iM1 effect.

One possible explanation of our results is that hand griprelated activity in cPMd may increase excitability in ipsilesional sensorimotor regions and thereby facilitate an increase in the gain of descending motor signals to the affected upper limb. This influence could become more important in patients with greater impairment, since cPMd is more useful for motor performance in more impaired patients (Johansen-Berg et al., 2002). As the hand region of $\mathrm{M} 1$ becomes less important in motor control with increasing corticospinal tract damage (Ward et al., 2007), an in- 
creased influence on that part of disconnected M1 might not enhance motor output in more impaired patients. However, more posterior parts of sensorimotor cortex may retain their direct projections to spinal cord motoneurons in some patients and hence may provide a better target for cPMd to influence motor output. Posterior shifts in the peak of sensorimotor cortex activation have been previously observed in stroke patients, presumably as a consequence of effective (or partial) disconnection of the hand area from the corticospinal tract (Pineiro et al., 2001). Corresponding posterior shifts in the TMS motor hot spot (Rossini et al., 1998) suggest that these more posterior regions are intimately involved in motor output to the affected hand. Activity during affected hand grip was indeed found more posteriorly with greater impairment in our own patient cohort (Fig. 4).

Another cortical motor region known to be more active in patients with greater impairment and/or more corticospinal tract damage is Brodmann area (BA) 4p (Ward et al., 2003b, 2006), in the deep part of the anterior bank of central sulcus. Here we found that CPMd TMS exerted greater grip-related influence on $\mathrm{BA} 4 \mathrm{p}$ in those patients for whom the paired-coil cPMd-M1 measure was most abnormal. By using both a clinical and neurophysiological measure as covariates in our fMRI analysis, we were able to identify two regions of the ipsilesional grip-related network via which the influence of cPMd increases in more impaired patients. This indicates changes in interregional influence within the motor network that relate to the impairment of corticospinal system function. A question for future research is how this reorganized interregional influences arises, including whether it is an inevitable consequence of corticospinal disruption by the subcortical lesions themselves or whether it can also be shaped by some forms of physical therapy or motor practice. Answering this question will require longitudinal studies that make specific therapeutic or practice manipulations.

More generally, the present concurrent TMS-fMRI approach can highlight state-dependent interactions between remote but interconnected regions across the brain (Bestmann et al., 2008; Ruff et al., 2006; Sack et al., 2007). Concurrent TMS-fMRI can provide a new type of additional information compared with paired-pulse double-coil approaches alone or purely correlative fMRI approaches without the causal TMS intervention. Relating BOLD signal changes directly to the physiological changes evoked by TMS inevitably demands the combination of more invasive recordings of neural activity with fMRI. The relationship between the observed BOLD signal changes reported here and the physiological inhibition or facilitation observed in our pairedcoil TMS experiment must therefore be considered with care. However, recent work has clearly demonstrated how the concurrent TMS-fMRI approach can be applied to highlight differences in TMS-evoked activity changes locally and in interconnected regions (Bestmann et al., 2008; Driver et al., 2009), including for pathological conditions such as depression (Li et al., 2004). We show how one can apply this technique to study state-dependent changes in interregional influences following stroke and how such changes relate to individual clinical and electrophysiological markers of residual motor function. Our present results relate only to the state-dependent influence of cPMd on other brain regions, but the present approach could now be used to study the influence of other cortical motor regions on surviving motor networks after stroke.

In general, interhemispheric PMd-M1 influences studied with paired-coil TMS can be inhibitory or facilitatory, depending on the exact conditioning intensity used (Bäumer et al., 2006). We have taken our results to indicate a shift in the balance toward net facilitation in the more impaired patients. The implication is that input from cPMd might now assist ipsilesional brain regions to produce movement. The fact that transient interference with the activity of cPMd using single-pulse TMS impairs movement of the paretic hand in stroke patients (Johansen-Berg et al., 2002) appears consistent with such a change to a facilitatory role. Interestingly, a different argument has been made for the possible role of cM1 (Hummel and Cohen, 2006). Using paired-coil TMS, Murase et al. (2004) found that, unlike healthy controls, stroke patients with unilateral motor deficits showed abnormally increased interhemispheric inhibition from $\mathrm{cM} 1$ before movement of the affected hand. They proposed that persisting interhemispheric inhibition from cM1 could interfere with movement controlled by the damaged hemisphere, contributing to motor impairment. Indeed, this reasoning led to a potential treatment approach in stroke: using low-frequency rTMS or cathodal transcranial direct-current stimulation, with the aim of reducing activity of cM1 and thereby promoting greater function in iM1 (for review, see Hummel and Cohen, 2006; Talelli and Rothwell, 2006; Nowak et al., 2009). It is unclear why input from cM1 should interfere with functioning of the damaged hemisphere, which appears to be facilitated by input from cPMd. One possibility is that control of inhibition from cM1 is normally managed by circuits in iM1 that suppress inputs before movement. If these are damaged by stroke, then the influence of cM1 will appear negative. Conversely, inputs from cPMd may normally assist production of certain types of movement (O'Shea et al., 2007a,b) and this facilitation may increase after damage to the lesioned hemisphere. Although the physiological signatures for $\mathrm{cM} 1$ and cPMd influences on iM1 appear very different, the commonality for both sets of observations is that interhemispheric influences from contralesional to ipsilesional motor regions, as assessed with paired-coil measures, are systematically more abnormal in patients with more impaired clinical motor function (supplemental Discussion, available at www.jneurosci.org as supplemental material).

In conclusion, our results indicate that contralesional PMd exerts a causal influence on ipsilesional sensorimotor regions that are active during movement of the weak hand that increases with impairment. Although previous work led to the hypothesis that cPMd is important for supporting recovered motor function, particularly in more impaired patients, here we were able to show for the first time via concurrent TMS-fMRI that the mechanism of this support is likely to be a remote, state-dependent influence on ipsilesional sensorimotor cortex that is stronger during grip with the paretic hand, more so in more impaired patients. Furthermore, physiological changes in interhemispheric cortical influences can explain unique aspects of motor system activity in stroke patients using their affected hand. More generally, this work highlights an important property of the CNS in that the functional influences of brain regions upon others are adaptable in clinically and behaviorally relevant ways.

\section{References}

Amassian VE, Stewart M (2003) Motor cortical and other cortical interneuronal networks that generate very high frequency waves. Suppl Clin Neurophysiol 56:119-142.

Amiez C, Kostopoulos P, Champod AS, Petrides M (2006) Local morphology predicts functional organization of the dorsal premotor region in the human brain. J Neurosci 26:2724-2731.

Andersson JL, Hutton C, Ashburner J, Turner R, Friston K (2001) Modeling geometric deformations in EPI time series. Neuroimage 13:903-919.

Baudewig J, Paulus W, Frahm J (2000) Artifacts caused by transcranial mag- 
netic stimulation coils and EEG electrodes in $\mathrm{T}(2)^{*}$-weighted echo-planar imaging. Magn Reson Imaging 18:479-484.

Baudewig J, Siebner HR, Bestmann S, Tergau F, Tings T, Paulus W, Frahm J (2001) Functional MRI of cortical activations induced by transcranial magnetic stimulation (TMS). Neuroreport 12:3543-3548.

Bäumer T, Bock F, Koch G, Lange R, Rothwell JC, Siebner HR, Münchau A (2006) Magnetic stimulation of human premotor or motor cortex produces interhemispheric facilitation through distinct pathways. J Physiol 572:857-868.

Benecke R, Meyer BU, Freund HJ (1991) Reorganisation of descending motor pathways in patients after hemispherectomy and severe hemispheric lesions demonstrated by magnetic brain stimulation. Exp Brain Res 83:419-426.

Bestmann S, Baudewig J, Frahm J (2003) On the synchronization of transcranial magnetic stimulation and functional echo-planar imaging. J Magn Reson Imaging 17:309-316.

Bestmann S, Baudewig J, Siebner HR, Rothwell JC, Frahm J (2004) Functional MRI of the immediate impact of transcranial magnetic stimulation on cortical and subcortical motor circuits. Eur J Neurosci 19:1950-1962.

Bestmann S, Baudewig J, Siebner HR, Rothwell JC, Frahm J (2005) BOLD MRI responses to repetitive TMS over human dorsal premotor cortex. Neuroimage 28:22-29.

Bestmann S, Ruff CC, Blankenburg F, Weiskopf N, Driver J, Rothwell JC (2008a) Mapping interregional influences with concurrent TMS-fMRI. Exp Brain Res 191:383-402.

Bestmann S, Swayne O, Blankenburg F, Ruff CC, Haggard P, Weiskopf N, Josephs O, Driver J, Rothwell JC, Ward NS (2008b) Dorsal premotor cortex exerts state-dependent causal influences on activity in contralateral primary motor and dorsal premotor cortex. Cereb Cortex 18:1281-1291.

Blankenburg F, Ruff CC, Bestmann S, Bjoertomt O, Eshel N, Josephs O, Weiskopf N, Driver J (2008) Interhemispheric effect of parietal TMS on somatosensory response confirmed directly with concurrent TMS-fMRI. J Neurosci 28:13202-13208.

Bohning DE, Shastri A, Nahas Z, Lorberbaum JP, Andersen SW, Dannels WR, Haxthausen EU, Vincent DJ, George MS (1998) Echoplanar BOLD fMRI of brain activation induced by concurrent transcranial magnetic stimulation. Invest Radiol 33:336-340.

Boudrias MH, McPherson RL, Frost SB, Cheney PD (2010) Output properties and organization of the forelimb representation of motor areas on the lateral aspect of the hemisphere in rhesus macaques. Cereb Cortex 20:169-186.

Bungert A, Bowtell RW (2008a) Simulating the effect of TMS-pulses on the evolution of magnetization. Paper presented at 16th Annual Meeting ISMRM, Toronto, ON, Canada, May. Abstr S3027.

Bungert A, Bowtell RW (2008b) Effects of the TMS coil on MR image quality in combined TMS/fMRI. Paper presented at 16th Annual Meeting ISMRM, Toronto, ON, Canada, May. Abstr S3028.

Chollet F, DiPiero V, Wise RJ, Brooks DJ, Dolan RJ, Frackowiak RS (1991) The functional anatomy of motor recovery after stroke in humans: a study with positron emission tomography. Ann Neurol 29:63-71.

Civardi C, Cantello R, Asselman P, Rothwell JC (2001) Transcranial magnetic stimulation can be used to test connections to primary motor areas from frontal and medial cortex in humans. Neuroimage 14:1444-1453.

Cramer SC (2004) Changes in motor system function and recovery after stroke. Restor Neurol Neurosci 22:231-238.

Cramer SC (2008) Repairing the human brain after stroke. I. Mechanisms of spontaneous recovery. Ann Neurol 63:272-287.

Cramer SC, Crafton KR (2006) Somatotopy and movement representation sites following cortical stroke. Exp Brain Res 168:25-32.

Deichmann R, Schwarzbauer C, Turner R (2004) Optimisation of the 3D MDEFT sequence for anatomical brain imaging: technical implications at 1.5 and 3 T. Neuroimage 21:757-767.

Driver J, Blankenburg F, Bestmann S, Vanduffel W, Ruff CC (2009) Concurrent brain-stimulation and neuroimaging for studies of cognition. Trends Cogn Sci 13:319-327.

Dum RP, Strick PL (2005) Frontal lobe inputs to the digit representations of the motor areas on the lateral surface of the hemisphere. J Neurosci 25:1375-1386.

Friston KJ, Holmes AP, Worsley KJ, Poline JP, Frith CD, Frackowiak RS (1994) Statistical parametric maps in functional imaging: a general linear approach. Hum Brain Mapp 2:189-210.

Friston KJ, Fletcher P, Josephs O, Holmes A, Rugg MD, Turner R (1998)
Event-related fMRI: characterizing differential responses. Neuroimage $7: 30-40$.

Gerloff C, Bushara K, Sailer A, Wassermann EM, Chen R, Matsuoka T, Waldvogel D, Wittenberg GF, Ishii K, Cohen LG, Hallett M (2006) Multimodal imaging of brain reorganization in motor areas of the contralesional hemisphere of well recovered patients after capsular stroke. Brain 129:791-808.

Gilio F, Conte A, Vanacore N, Frasca V, Inghilleri M, Berardelli A (2007) Excitatory and inhibitory after-effects after repetitive magnetic transcranial stimulation (rTMS) in normal subjects. Exp Brain Res 176:588-593.

Hanakawa T, Mima T, Matsumoto R, Abe M, Inouchi M, Urayama S, Anami K, Honda M, Fukuyama H (2009) Stimulus-response profile during single-pulse transcranial magnetic stimulation to the primary motor cortex. Cereb Cortex 19:2605-2615.

Heller A, Wade DT, Wood VA, Sunderland A, Hewer RL, Ward E (1987) Arm function after stroke: measurement and recovery over the first three months. J Neurol Neurosurg Psychiatry 50:714-719.

Hummel FC, Cohen LG (2006) Non-invasive brain stimulation: a new strategy to improve neurorehabilitation after stroke? Lancet Neurol 5:708-712.

Johansen-Berg H, Rushworth MF, Bogdanovic MD, Kischka U, Wimalaratna S, Matthews PM (2002) The role of ipsilateral premotor cortex in hand movement after stroke. Proc Natl Acad Sci U S A 99:14518-14523.

Josephs O, Deichmann R, Turner R (2000) Trajectory measurement and generalised reconstruction in rectilinear EPI. S517. Paper presented at 8th Annual Meeting of the International Society for Magnetic Resonance in Medicine, Denver, Co, April.

Koch G, Franca M, Del Olmo MF, Cheeran B, Milton R, Alvarez Sauco M, Rothwell JC (2006) Time course of functional connectivity between dorsal premotor and contralateral motor cortex during movement selection. J Neurosci 26:7452-7459.

Li X, Tenebäck CC, Nahas Z, Kozel FA, Large C, Cohn J, Bohning DE, George MS (2004) Interleaved transcranial magnetic stimulation/functional MRI confirms that lamotrigine inhibits cortical excitability in healthy young men. Neuropsychopharmacology 29:1395-1407.

Lotze M, Markert J, Sauseng P, Hoppe J, Plewnia C, Gerloff C (2006) The role of multiple contralesional motor areas for complex hand movements after internal capsular lesion. J Neurosci 26:6096-6102.

Lu MT, Preston JB, Strick PL (1994) Interconnections between the prefrontal cortex and the premotor areas in the frontal lobe. J Comp Neurol 341:375-392.

Macey PM, Macey KE, Kumar R, Harper RM (2004) A method for removal of global effects from fMRI time series. Neuroimage 22:360-366.

Marconi B, Genovesio A, Giannetti S, Molinari M, Caminiti R (2003) Callosal connections of dorso-lateral premotor cortex. Eur J Neurosci 18:775-788.

Mars RB, Klein MC, Neubert FX, Olivier E, Buch ER, Boorman ED, Rushworth MF (2009) Short-latency influence of medial frontal cortex on primary motor cortex during action selection under conflict. J Neurosci 29:6926-6931.

Mazevet D, Meunier S, Pradat-Diehl P, Marchand-Pauvert V, PierrotDeseilligny E (2003) Changes in propriospinally mediated excitation of upper limb motoneurons in stroke patients. Brain 126:988-1000.

Mochizuki H, Huang YZ, Rothwell JC (2004) Interhemispheric interaction between human dorsal premotor and contralateral primary motor cortex. J Physiol 561:331-338.

Modugno N, Nakamura Y, MacKinnon CD, Filipovic SR, Bestmann S, Berardelli A, Rothwell JC (2001) Motor cortex excitability following short trains of repetitive magnetic stimuli. Exp Brain Res 140:453-459.

Murase N, Duque J, Mazzocchio R, Cohen LG (2004) Influence of interhemispheric interactions on motor function in chronic stroke. Ann Neurol 55:400-409.

Nowak DA, Grefkes C, Ameli M, Fink GR (2009) Interhemispheric competition after stroke: brain stimulation to enhance recovery of function of the affected hand. Neurorehabil Neural Repair 23:641-656.

O'Shea J, Johansen-Berg H, Trief D, Göbel S, Rushworth MF (2007a) Functionally specific reorganization in human premotor cortex. Neuron 54:479-490.

O'Shea J, Sebastian C, Boorman ED, Johansen-Berg H, Rushworth MF (2007b) Functional specificity of human premotor-motor cortical interactions during action selection. Eur J Neurosci 26:2085-2095. 
O'Shea J, Taylor PC, Rushworth MF (2008) Imaging causal interactions during sensorimotor processing. Cortex 44:598-608.

Pineiro R, Pendlebury S, Johansen-Berg H, Matthews PM (2001) Functional MRI detects posterior shifts in primary sensorimotor cortex activation after stroke: evidence of local adaptive reorganization? Stroke 32:1134-1139.

Rossi S, Hallett M, Rossini PM, Pascual-Leone A (2009) Safety, ethical considerations, and application guidelines for the use of transcranial magnetic stimulation in clinical practice and research. Clin Neurophysiol 120:2008-2039.

Rossini PM, Caltagirone C, Castriota-Scanderbeg A, Cicinelli P, Del Gratta C, Demartin M, Pizzella V, Traversa R, Romani GL (1998) Hand motor cortical area reorganization in stroke: a study with fMRI, MEG and TCS maps. Neuroreport 9:2141-2146.

Ruff CC, Blankenburg F, Bjoertomt O, Bestmann S, Freeman E, Haynes JD, Rees G, Josephs O, Deichmann R, Driver J (2006) Concurrent TMSfMRI and psychophysics reveal frontal influences on human retinotopic visual cortex. Curr Biol 16:1479-1488.

Sack AT (2006) Transcranial magnetic stimulation, causal structurefunction mapping and networks of functional relevance. Curr Opin Neurobiol 16:593-599.

Sack AT, Kohler A, Bestmann S, Linden DEJ, Dechent P, Goebel R, Baudewig J (2007) Visualizing virtual brain lesions: simultaneous fMRI and TMS during visuospatial judgements. Cereb Cortex 17:2841-2852.

Schaechter JD, Perdue KL (2008) Enhanced cortical activation in the contralesional hemisphere of chronic stroke patients in response to motor skill challenge. Cereb Cortex 18:638-647.

Schaechter JD, Perdue KL, Wang R (2008) Structural damage to the corticospinal tract correlates with bilateral sensorimotor cortex reorganization in stroke patients. Neuroimage 39:1370-1382.

Schluter ND, Rushworth MF, Passingham RE, Mills KR (1998) Temporary interference in human lateral premotor cortex suggests dominance for the selection of movements: a study using transcranial magnetic stimulation. Brain 121:785-799.

Schluter ND, Rushworth MF, Mills KR, Passingham RE (1999) Signal-, set-, and movement-related activity in the human premotor cortex. Neuropsychologia 37:233-243.

Seitz RJ, Höflich P, Binkofski F, Tellmann L, Herzog H, Freund HJ (1998) Role of the premotor cortex in recovery from middle cerebral artery infarction. Arch Neurol 55:1081-1088.

Shastri A, George MS, Bohning DE (1999) Performance of a system for interleaving transcranial magnetic stimulation with steady-state magnetic resonance imaging. Electroencephalogr Clin Neurophysiol Suppl 51: $55-64$.

Siebner HR, Peller M, Willoch F, Auer C, Bartenstein P, Drzezga A, Schwaiger M, Conrad B (1999) Imaging functional activation of the auditory cor- tex during focal repetitive transcranial magnetic stimulation of the primary motor cortex in normal subjects. Neurosci Lett 270:37-40.

Stinear JW, Byblow WD (2004) The contribution of cervical propriospinal premotoneurons in recovering hemiparetic stroke patients. J Clin Neurophysiol 21:426-434.

Talelli P, Rothwell J (2006) Does brain stimulation after stroke have a future? Curr Opin Neurol 19:543-550.

Talelli P, Ewas A, Waddingham W, Rothwell JC, Ward NS (2008) Neural correlates of age-related changes in cortical neurophysiology. Neuroimage 40:1772-1781.

Tohka J, Foerde K, Aron AR, Tom SM, Toga AW, Poldrack RA (2008) Automatic independent component labeling for artifact removal in fMRI Neuroimage 39:1227-1245.

Ward NS (2004) Functional reorganization of the cerebral motor system after stroke. Curr Opin Neurol 17:725-730.

Ward NS (2006) The neural substrates of motor recovery after focal damage to the central nervous system. Arch Phys Med Rehabil 87:S30-S35.

Ward NS, Brown MM, Thompson AJ, Frackowiak RS (2003a) Neural correlates of motor recovery after stroke: a longitudinal fMRI study. Brain 126:2476-2496.

Ward NS, Brown MM, Thompson AJ, Frackowiak RS (2003b) Neural correlates of outcome after stroke: a cross-sectional fMRI study. Brain 126:1430-1448.

Ward NS, Newton JM, Swayne OB, Lee L, Thompson AJ, Greenwood RJ, Rothwell JC, Frackowiak RS (2006) Motor system activation after subcortical stroke depends on corticospinal system integrity. Brain 129:809_ 819 .

Ward NS, Newton JM, Swayne OB, Lee L, Frackowiak RS, Thompson AJ, Greenwood RJ, Rothwell JC (2007) The relationship between brain activity and peak grip force is modulated by corticospinal system integrity after subcortical stroke. Eur J Neurosci 25:1865-1873.

Weiller C, Chollet F, Friston KJ, Wise RJ, Frackowiak RS (1992) Functional reorganization of the brain in recovery from striatocapsular infarction in man. Ann Neurol 31:463-472.

Weiskopf N, Sitaram R, Josephs O, Veit R, Scharnowski F, Goebel R, Birbaumer N, Deichmann R, Mathiak K (2007) Real-time functional magnetic resonance imaging: methods and applications. Magn Reson Imaging 25:989-1003.

Weiskopf N, Josephs O, Ruff CC, Blankenburg F, Featherstone E, Thomas A, Bestmann S, Driver J, Deichmann R (2009) Image artifacts in concurrent transcranial magnetic stimulation (TMS) and fMRI caused by leakage currents: modeling and compensation. J Magn Reson Imaging 29:1211-1217.

Wise SP, Boussaoud D, Johnson PB, Caminiti R (1997) Premotor and parietal cortex: corticocortical connectivity and combinatorial computations. Annu Rev Neurosci 20:25-42. 